\title{
The Effects of Prognostic Factors in Idiopathic Sudden Hearing Loss
}

\author{
Suphi Bulğurcu ${ }^{1}$ Behçet Şahin² Gökhan Akgül ${ }^{3}$ ilker Burak Arslan ${ }^{3}$ ibrahim Çukurova ${ }^{3}$
}

${ }^{1}$ Department of Otorhinolaryngology, Başkale State Hospital, Başkale, Van, Van 65600, Turkey

2 Department of Otorhinolaryngology, Amasya Sabuncuoğlu Şerefeddin Training and Research Hospital, Amasya, Turkey

${ }^{3}$ Department of Otorhinolaryngology, Tepecik Training and Research Hospital, İzmir, Turkey

\author{
Address for correspondence Suphi Bulğurcu, MD, Department of \\ Otorhinolaryngology, Başkale State Hospital, Başkale, Van, Van \\ 65600, Turkey (e-mail: suphibulg@yahoo.com).
}

Int Arch Otorhinolaryngol 2018;22:33-37.

\begin{abstract}
Introduction Sudden hearing loss is one of the otologic emergencies. The treatment of this disease is affected negatively by some prognostic factors.

Objective In this study, the effects of early treatment initiation in patients with idiopathic sudden hearing loss and of prognostic factors in early treated patients were investigated.

Methods Out of the 216 patients admitted between September 2007 and September 2015, 154 were identified as having idiopathic sudden hearing loss; they were followedup for a mean time of 7.4 months, and evaluated retrospectively. The effects of several parameters on the success of the treatment were statistically evaluated, such as the time the treatment was initiated, being of the female gender, the severity of the hearing loss, having descending type audiogram patterns, being older than 60 years old, and the co-presence of vertigo.

Results Success rates were found to be significantly higher in idiopathic hearing loss patients that were admitted within the first week $(p<0.05)$ of the onset of the hearing loss. However, the outcomes were found to be similar when patients admitted within the first 3 days and 4-7 days after the occurrence of the hearing loss were compared $(p>0.05)$. Parameters such as female gender, severe hearing loss, descending type

\section{Keywords}

- sudden hearing loss

- prognosis

- time audiogram, being older than 60 years old, and co-presence of vertigo didn't reveal statistically significant effects on the outcome $(p>0.05)$.

Conclusion The aforementioned prognostic factors, which are well-known in the literature, did not have significant effects when the idiopathic sudden hearing loss treatment was initiated within the first 7 days of the onset of the hearing loss.
\end{abstract}

\section{Introduction}

Sudden hearing loss is an otologic emergency with an annual incidence of 5-20 patients per 100,000 individuals. The diagnostic criterion for sudden hearing loss is having a hearing loss greater than 30 decibels $(\mathrm{dB})$ in 3 consecutive frequencies within 3 days of the onset of the symptom. Studies show that males and females are equally affected, and the average age of the onset is reported to be between $43-53$ years. It is also reported that $28-57 \%$ of the patients received

November 9, 2016

accepted

April 1, 2017

published online

May 17, 2017
DOI https://doi.org/

10.1055/s-0037-1603108. ISSN 1809-9777.
Copyright $\odot 2018$ by Thieme Revinter

Publicações Ltda, Rio de Janeiro, Brazil
License terms

(요 (1) $\Theta \circledast$ 
has ear fullness, tinnitus, vertigo of varying severity, and balance disorders. ${ }^{1}$

In the study by Kuhn et al, the underlying etiologies in $7-45 \%$ of the patients were identified. They categorized the causes as autoimmune, vascular, infectious, metabolic, neoplastic, neurologic, otologic, traumatic, toxic, and functional. The cases with no identifiable etiology were referred to as idiopathic sudden hearing loss (ISHL). The existing theories regarding the pathophysiology of ISHL include cochlear membrane rupture, vascular events, and viral infections. $^{2}$

There are no clear treatment recommendations for patients with sudden hearing loss of unidentified etiology in the literature. ${ }^{3}$ On the other hand, several prognostic factors, including being of the female gender, late treatment initiation, the presence of descending type audiogram patterns, the co-presence of vertigo, severe hearing loss, and being older than 60 years old and younger than 15 years old were reported to have negative effects on the recovery process. Full recovery is defined as achieving at least a $25-\mathrm{dB}$ improvement in pure tone average (average of 500, 1,000, 2,000 and $4,000 \mathrm{~Hz}$ ), or a return to pre-loss values after treatment. When the improvement is between $10-24 \mathrm{~dB}$, the cases are considered as partial recoveries. An improvement of less than $10 \mathrm{~dB}$ is deemed no recovery. ${ }^{4,5}$

In this study, the association between the time the treatment was initiated and the success of it, as well as the effects of the negative prognostic factors, such as being of the female gender, having severe hearing loss, the co-presence of vertigo, the presence of descending type audiogram patterns, and advanced age on the outcomes of the patients treated within the first week were investigated.

\section{Materials and Methods}

A total of 216 patients with sudden hearing loss and showing a loss of at least $30 \mathrm{~dB}$ at three consecutive frequencies, admitted between September 2007 and September 2015, were evaluated retrospectively, after obtaining the approval of our local ethics committee. All patients were hospitalized and questioned for any infection symptoms for the past 10 days, trauma history, systemic diseases, neurologic and otologic conditions, and use of any ototoxic medications. All patients underwent contrast magnetic resonance imaging for any possible intracranial pathologies. Blood samples were collected and analyzed for autoimmune and hematologic conditions, as well as viral infections. Laboratory examinations included tests for: full blood count; erythrocyte sedimentation rate; prothrombin time; serum glucose, cholesterol, lipids, urea and creatinine concentrations; viral serological tests for Epstein-Barr, rubella, cytomegalovirus, human immunodeficiency, hepatitis B and C; fluorescent treponemal antibody (FTA) test for Treponema pallidum infection; serum thyroid hormones; and antigen-nonspecific serologic tests for autoimmune diseases (anti-nuclear antigen [ANA], anti-smooth muscle antibody [ASMA], anti-deoxyribonucleic acid antibody [anti-DNA], and rheumatoid factor $[R F])$. The patients were followed-up for at least 6 months. No etiology could be identified in 154 of the patients (76 male, 78 female) with an average age of 63.94 years (range: 17-74 years), and they were eventually diagnosed as having ISHL. The right ear was affected in 89 patients, while 65 had left-sided hearing loss.

All patients with ISHL were treated according to our department's standard protocol ( - Table $\mathbf{1}$ ).

The degree of hearing loss was classified as mild (26-40 dB), moderate (41-55 dB), moderately severe (56-70 dB), severe (71-90 dB) and profound (> $90 \mathrm{~dB})$, as proposed by Shaia and Sheehy. ${ }^{6}$ Three treatment success categories were established according to the extent of the recovery. The groups were as follows: full recovery (that is, an improvement of at least a $25-\mathrm{dB}$ in pure tone average, or a return to pre-loss values after treatment), partial recovery (that is, a pure tone average improvement between $10-24 \mathrm{~dB}$ ) and no recovery (that is, an improvement of less than $10 \mathrm{~dB}$ ). The patients belonged to one of the four treatment initiation time groups. In the early treatment group, the treatment was initiated within 0-3 days (group 1) and 4-7 days (group 2) after the hearing loss occurred, while the late treatment group consisted of patients whose treatment was initiated between 8-14 days (group 3) and 15-30 days (group 4 ) after the onset of the hearing loss.

Severe hearing loss was defined as having a loss greater than $70 \mathrm{~dB}$. Four distinct audiogram type groups, namely sloping, ascending, flat, and total, according to Sheehy's classification, were established. ${ }^{7}$

In the early treatment group, the effects on the success of the treatment of being female, having severe hearing loss, showing descending type audiogram patterns, and being older than 60 years old were evaluated.

Table 1 Treatment protocol for patients with idiopathic sudden hearing loss

\begin{tabular}{|l|l|l|l|l|}
\hline Drug & Duration of medication & Dose interval & Amount of dose & Drug administration route \\
\hline Dexamethasone & 5 days & $1 \times 1$ & $0.5 \mathrm{~mL}$ & intratympanic \\
\hline Methylprednisolone & 1 day & $1 \times 1$ & $250 \mathrm{mg}$ & intravenous \\
\hline Heparin sodium & 10 days & $2 \times 1$ & $1 \mathrm{~mL}$ & intravenous \\
\hline Pentoxifylline & 10 days & $2 \times 1$ & $4 \mathrm{~mL}$ & intravenous \\
\hline Pantoprazole & 10 days & $1 \times 1$ & $40 \mathrm{mg}$ & peroral \\
\hline Trimetazidine & 10 days & $2 \times 1$ & $20 \mathrm{mg}$ & peroral \\
\hline B vitamin complex & 10 days & $1 \times 1$ & $1 \mathrm{mg}$ & peroral \\
\hline
\end{tabular}


Table 2 Recovery rate, audiogram types and coexistent vertigo presented according to the treatment initiation time

\begin{tabular}{|l|l|l|l|l|l|}
\hline $\begin{array}{l}\text { Treatment initiation } \\
\text { time (days)/N }\end{array}$ & Mean age & $\begin{array}{l}\text { Gender } \\
(\mathrm{F} / \mathrm{M})\end{array}$ & $\begin{array}{l}\text { Recovery rate } \\
\text { Complete/Partial/No }\end{array}$ & $\begin{array}{l}\text { Audiogram types } \\
\mathrm{S} / \mathrm{A} / \mathrm{F} / \mathrm{T}\end{array}$ & $\begin{array}{l}\text { Coexistent } \\
\text { vertigo }\end{array}$ \\
\hline $0-3$ (group 1) & 43.71 & $31 / 30$ & $13 / 18 / 30$ & $50 / 2 / 5 / 4$ & 39 \\
\hline $4-7$ (group 2) & 48.46 & $30 / 30$ & $16 / 18 / 26$ & $34 / 5 / 11 / 10$ & 28 \\
\hline $8-15$ (group 3) & 46.37 & $13 / 11$ & $2 / 7 / 15$ & $6 / 1 / 8 / 9$ & 9 \\
\hline $15-30$ (group 4) & 49.1 & $4 / 5$ & $0 / 2 / 7$ & $2 / 0 / 2 / 5$ & 2 \\
\hline
\end{tabular}

Abbreviations: F, female; $\mathrm{M}$, male.

Note: Audiogram types: Sloping (S), ascending (A), flat (F), and total (T).

Patients with bilateral sudden hearing loss, describing a loss that had begun more than 30 days prior to their consultations, and those younger than 15 years old were excluded from the study.

A dataset was built using the International Business Machines Statistical Package for the Social Sciences (IBM SPSS, IBM Corp., Armonk, NY, US). Numerical and categorical data were analyzed using the Student's t- and the chi-square tests where appropriate. Values of $p<0.05$ were considered statistically significant.

\section{Results}

A total of 78 females (mean age: $45 \pm 2.7$ years) and 76 males (mean age: $46 \pm 3.4$ years) diagnosed as having ISHL were included in the study. The average time of admission was 6.21 days. Recovery rate, audiogram types and coexistent vertigo were presented according to the treatment initiation time in - Table 2. Moderate (41-55 dB) and moderately severe (56-70 dB) hearing losses are the most encountered audiogram types with ISHL (-Table $\mathbf{3}$ ).

In 66 patients, the causes of the sensorineural hearing loss were identified as: viral infections (21 patients), systemic disease (14 patients), trauma (13 patients), vascular pathologies (6 patients), ototoxicity ( 3 patients), vestibulocochlear nerve compression ( 2 patients), autoimmune conditions (2 patients), and Meniere's disease (1 patient). Regarding the remaining 154 patients with ISHL, there was a statistically significant association between treatment initiation times and recovery degrees, when early and late treatment groups were compared ( $p=0.043)$. The degrees of recovery were similar between the patients treated at 0-3 days and 4-7 days $(p>0.05)$, and between the patients treated at $8-14$ days and $15-30$ days $(p>0.05)$
(-Table 2). The effects of gender, having a loss greater than $70 \mathrm{~dB}$, being older than 60 years, having descending type audiogram patterns and presence of vertigo in early treated patients were summarized in - Table 4.

\section{Discussion}

No etiology can be detected in $\sim 70 \%$ of patients with sudden hearing loss, and such cases are eventually identified as ISHL. ${ }^{8}$ Some of these patients show spontaneous recovery. ${ }^{9}$ Various treatment protocols are available in the literature, and steroids have been reported to be the most effective treatment method in general. ${ }^{10,11}$ Chen et al found that intratympanic steroids were more effective than systemic steroids in the treatment of sudden hearing loss. ${ }^{12}$ Ding et al reported that the first choice in the treatment of ISHL should be systemic steroids. ${ }^{13}$ However, Arastou et al reported that the co-administration of systemic and intratympanic steroids was more effective in sudden hearing loss. ${ }^{14}$ We prefer to administer systemic and intratympanic steroids together.

On the other hand, different protocols reveal different recovery rates. In concordance with our findings, the most important issue in the treatment is reported to be the early initiation. ${ }^{15}$ In the study by Lee et al, 289 sudden hearing loss cases were evaluated, and the recovery rates were found to be of $73.8 \%$ when the treatment was initiated within 3 days, and of $87.2 \%$ when it was initiated within 7 days of the onset of the hearing loss. ${ }^{16}$ Uysal et al studied 96 ISHL patients and reported better recovery rates when the treatment began within the first week. ${ }^{17}$ Similarly, Cho et al. found significantly higher recovery rates $(88 \%)$ in patients who were treated within the first 3 days. ${ }^{18}$ Contradicting results are also present in the literature. ${ }^{19}$ In the

Table 3 Relationship between recovery rates with treatment initiation time and degree of hearing loss

\begin{tabular}{|l|l|l|l|l|l|}
\hline $\begin{array}{l}\text { Treatment initiation } \\
\text { time (days)/N }\end{array}$ & Mild C/P/N & Moderate C/P/N & $\begin{array}{l}\text { Moderately } \\
\text { severe C/P/N }\end{array}$ & Severe C/P/N & Profound C/P/N \\
\hline $0-3($ group 1) & $2 / 0 / 0$ & $1 / 4 / 6$ & $2 / 4 / 7$ & $5 / 6 / 8$ & $3 / 4 / 9$ \\
\hline $4-7$ (group 2) & $2 / 2 / 1$ & $3 / 4 / 6$ & $3 / 1 / 6$ & $6 / 7 / 5$ & $2 / 4 / 8$ \\
\hline $8-15$ (group 3) & $0 / 0 / 3$ & $1 / 2 / 2$ & $0 / 2 / 2$ & $1 / 3 / 6$ & $0 / 0 / 2$ \\
\hline $15-30$ (group 4) & $0 / 0 / 0$ & $0 / 1 / 1$ & $0 / 1 / 2$ & $0 / 0 / 3$ & $0 / 0 / 1$ \\
\hline
\end{tabular}

Abbreviations: C, complete recovery; P, partial recovery; $N$, no recovery. 
Table 4 Effects of gender, having a hearing loss greater than $70 \mathrm{~dB}$, being older than 60 years, having descending type audiogram patterns, and co-presence of vertigo in the early treated patients

\begin{tabular}{|l|l|l|l|l|l|l|}
\hline & Full Recovery & & Partial Recovery & & No Recovery & \\
\hline & & $p$ & & $p$ & & $p$ \\
\hline Gender & & 0.831 & & 0.691 & & 1.0 \\
\hline Female & 14 & 19 & 28 & & & \\
\hline Male & 15 & 17 & 28 & & & \\
\hline Hearing loss & & 0.837 & & 0.949 & & 0.295 \\
\hline$>70 \mathrm{~dB}$ & 16 & 21 & 30 & & & \\
\hline$\leq 70 \mathrm{~dB}$ & 13 & 15 & 26 & & & \\
\hline Age & & 0.746 & & 0.001 & & 0.001 \\
\hline$>60$ years old & 7 & 0 & 25 & & & \\
\hline$\leq 60$ years old & 22 & 36 & 31 & & & \\
\hline Audiogram type & & 0.184 & & 0.001 & & 0.004 \\
\hline Sloping & 23 & 31 & 30 & & & \\
\hline Others & 6 & 5 & 26 & & & \\
\hline Vertigo & 13 & 0.192 & & 0.708 & & 0.143 \\
\hline Presence & 16 & 19 & 35 & & & \\
\hline Absence & 17 & 21 & & & \\
\hline
\end{tabular}

present work, which was conducted with 154 ISHL patients, treatment success rates were significantly higher when the treatment was initiated within the first week.

Some authors suggest that being of the female gender is a negative factor for the success of the treatment. However, several contradicting reports indicating no differences between genders are also present. ${ }^{4,16,20,21}$ We also did not find any significant association between gender and treatment success.

There is a strong negative correlation between age and prognosis. A great deal of studies report that prognosis is significantly better in patients younger than 60 years of age. ${ }^{2,20-22}$ Although $75 \%$ of the patients that achieved full recovery were under the age of 60 , no statistical significance could be obtained. On the other hand, several studies failed to show an association between age and prognosis. ${ }^{23,24}$

Severe hearing loss is indicative of serious cochlear damage, and leads to poorer treatment success rates. Milder cases are reported to attain better treatment results. ${ }^{16,21,22}$ However, in our study, $55 \%$ of the patients with full recovery and $58 \%$ of the patients with partial recovery had a loss greater than $70 \mathrm{~dB}$. This may partially be due to the fact that patients with severe hearing loss were admitted to the hospital earlier.

The patients in our study presented four audiogram types, namely descending, ascending, flat and total loss. The descending type was present in 54\% of our cases. Various prevalence data are available regarding the audiogram types in sudden hearing loss patients. ${ }^{15}$ However, it is observed that the cases showing descending type audiograms have the poorest treatment success rates. Chang et al stated that a significant association could be made between the audiogram types and the treatment success rates. ${ }^{21,25}$ But, in our study, we did not detect any association between audiogram types and treatment success.

Inflammatory response in specific cochlear areas may extend beyond the barriers in the anterior labyrinthine region, and may reach the vestibule and semicircular channels, consequently triggering vestibular symptoms, in addition to sudden hearing loss. The co-presence of vertigo is shown to worsen the treatment outcomes in sudden hearing loss cases. ${ }^{26,27}$ We also found lower success rates in patients with accompanying vertigo without statistical significance.

\section{Conclusion}

In the present study, we decided that, in ISHL patients, when the treatment was initiated within the first 7 days of the onset of the hearing loss, the recovery rate was increased. We also found that the effect of other prognostic factors was less significant in the cases of early treatment. Further studies about early treatment in ISHL might contribute to our study.

Conflicts of Interest

The authors have no conflicts of interest to disclose.

\section{Reference}

1 Rauch SD. Intratympanic steroids for sensorineural hearing loss. Otolaryngol Clin North Am 2004;37(05):1061-1074

2 Kuhn M, Heman-Ackah SE, Shaikh JA, Roehm PC. Sudden sensorineural hearing loss: a review of diagnosis, treatment, and prognosis. Trends Amplif 2011;15(03):91-105 
3 Baloğlu O, Olgun G, Saraç S. İdiyopatik ani sensörinöral işitme kaybı tedavisi. Hacettepe Tıp Dergisi 2007;38:26-32

4 Xenellis J, Karapatsas I, Papadimitriou N, et al. Idiopathic sudden sensorineural hearing loss: prognostic factors. J Laryngol Otol 2006;120(09):718-724

5 Byl FM Jr. Sudden hearing loss: eight years' experience and suggested prognostic table. Laryngoscope 1984;94(5 Pt 1):647-661

6 Shaia FT, Sheehy JL. Sudden sensori-neural hearing impairment: a report of 1,220 cases. Laryngoscope 1976;86(03):389-398

7 Sheehy JL. Vasodilator therapy in sensory-neural hearing loss. Laryngoscope 1960;70:885-914

8 Chau JK, Lin JR, Atashband S, Irvine RA, Westerberg BD. Systematic review of the evidence for the etiology of adult sudden sensorineural hearing loss. Laryngoscope 2010;120(05): 1011-1021

9 Mattox DE, Simmons FB. Natural history of sudden sensorineural hearing loss. Ann Otol Rhinol Laryngol 1977;86(4 Pt 1):463-480

10 Tsai HT, Hsueh N, Huang CM, Lin HC. Intratympanic steroid injection as a first-line therapy in uremia patients with sudden sensorineural hearing loss. Acta Otolaryngol 2015;135(08): 786-790

11 Eftekharian A, Amizadeh M. Pulse steroid therapy in idiopathic sudden sensorineural hearing loss: A randomized controlled clinical trial. Laryngoscope 2016;126(01):150-155

12 Chen P, Wang S, Zhang Y, Huang H, Zhang C, Xiao Z. [Intratympanic versus systemic steroid initial treatment for idiopathic sudden hearing loss: a Meta-analysis]. Lin Chung Er Bi Yan Hou Tou Jing Wai Ke Za Zhi 2015;29(22):1970-1977

13 Ding XY, Cui TT, Feng GD, Gao ZQ. [Intratympanic versus systemic steroid treatment for idiopathic sudden hearing loss: a metaanalysis]. Zhonghua Er Bi Yan Hou Tou Jing Wai Ke Za Zhi 2013; 48(05):412-416

14 Arastou S, Tajedini A, Borghei P. Combined intratympanic and systemic steroid therapy for poor-prognosis sudden sensorineural hearing loss. Iran J Otorhinolaryngol 2013;25(70):23-28

15 Lloyd SK. Sudden sensorineural hearing loss: early diagnosis improves outcome. Br J Gen Pract 2013;63(613):e592-e594
16 Lee HS, Lee YJ, Kang BS, Lee BD, Lee JS. A clinical analysis of sudden sensorineural hearing loss cases. Korean J Audiol 2014;18(02): 69-75

17 Uysal İÖ, Müderris T, Polat K, Yüce S, Gültürk S. Is the time from the onset to the treatment a prognostic indicator for hearing recovery in idiopathic sudden sensorineural hearing loss? Kulak Burun Bogaz Ihtis Derg 2015;25(02):70-76

18 Cho CS, Choi YJ. Prognostic factors in sudden sensorineural hearing loss: a retrospective study using interaction effects. Rev Bras Otorrinolaringol (Engl Ed) 2013;79(04):466-470

19 Siegel LG. The treatment of idiopathic sudden sensorineural hearing loss. Otolaryngol Clin North Am 1975;8(02):467-473

20 Edizer DT, Çelebi Ö, Hamit B, Baki A, Yiğit Ö. Recovery of Idiopathic Sudden Sensorineural Hearing Loss. J Int Adv Otol 2015;11(02): 122-126

21 Chang NC, Ho KY, Kuo WR. Audiometric patterns and prognosis in sudden sensorineural hearing loss in southern Taiwan. Otolaryngol Head Neck Surg 2005;133(06):916-922

22 Harada H, KatoT. Prognosis for sudden sensorineural hearing loss: a retrospective study using logistical regression analysis. Int Tinnitus J 2005;11(02):115-118

23 Zadeh MH, Storper IS, Spitzer JB. Diagnosis and treatment of sudden-onset sensorineural hearing loss: a study of 51 patients. Otolaryngol Head Neck Surg 2003;128(01):92-98

24 Mamak A, Yilmaz S, Cansiz H, Inci E, Güçlü E, Dereköylü L. A study of prognostic factors in sudden hearing loss. Ear Nose Throat J 2005;84(10):641-644

25 Cvorović L, Deric D, Probst R, Hegemann S. Prognostic model for predicting hearing recovery in idiopathic sudden sensorineural hearing loss. Otol Neurotol 2008;29(04):464-469

26 Bogaz EA, Maranhão AS, Inoue DP, Suzuki FA, Penido NdeO. Variables with prognostic value in the onset of idiopathic sudden sensorineural hearing loss. Rev Bras Otorrinolaringol (Engl Ed) 2015;81(05):520-526

27 Ceylan A, Celenk F, Kemaloğlu YK, Bayazit YA, Göksu N, Ozbilen S. Impact of prognostic factors on recovery from sudden hearing loss. J Laryngol Otol 2007;121(11):1035-1040 